\title{
Autorität und ihre Legitimierung - ein schwieriges Thema
}

\section{Jean Martin}

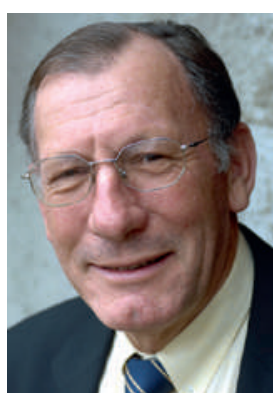

Damien R. Eloge de l'autorité. Paris: Armand Colin; 2014. Die angeführten Zitate sind einem in der Wochenzeitschrift Marianne publizierten Interview vom 12. Dezember 2014 (70-73) entnommen.

2 Siehe zu diesem Punkt den ausgezeichneten Artikel von Prof. Yves Sandoz, «Ce peuple qu a toujours raison». Le Temps (Genf), 17. Dezember 2014, S. 10

3 Bertrand Piccard zum Thema Autorität in seinem neuesten Buch Changer d'altitude: «Le but d'une relation devrait toujours être de construire une situation win-win. La seule exception est la situation hiérarchique dan laquelle un chef peut être contraint de donner des ordres" [qui peuvent ne pas plaire au subordonné].
In den letzten Jahrzehnten versteht sich Autorität (von Personen oder Institutionen) nicht mehr von selbst, sie wird in Frage gestellt bzw. «ist gar nicht mehr da». Der Philosoph Robert Damien widmet diesem Thema ein Buch [1]. Er unterstreicht die etymologische Bedeutung des Begriffs Autorität, der Fähigkeit, sich zu erhöhen, gemeinsam mehr und besser zu sein. Robert Damien: «Wir erleben keine Autoritätskrise, sondern eine Krise der Autoritäten. In der Demokratie gibt es eine Vielfalt an Autoritäten. Sie sind legitim, definieren unsere Zugehörigkeit, stehen jedoch in Konkurrenz zueinander. In dieser Hinsicht müssten wir zu einem ‘kohärenten Pluralismus> gelangen.»

Eine grosse Herausforderung: «Wie können wir mehrere und doch gleichzeitig nur einer sein? Wie gleichzeitig konventionell und ökologisch, Franzose - oder Schweizer - und Europäer, international und national? Wir erleben gerade eine Krise der Idealisierungen, der symbolischen Glaubenswerte, die unserer Geschichte ein Gesicht geben.» Gleichzeitig tauchen mit der digitalen Revolution und der Macht der Medien zwei neue Phänomene auf. Die Macht der Medien bereitet der mehr oder weniger "sanften Diktatur», die heute von der öffentlichen Meinung ausgeübt wird, den Weg. Ein echtes Thema auch in der Schweiz, wo einige die Sakralisierung einer sich nie irrenden Vox populi betreiben ... [2]. Dabei wird vergessen, wie riskant es ist, Fragen, die so komplex und mit anderen Themen verknüpft sind, dass es für eine richtige Meinungsbildung unabdingbar ist, sich vorab ausreichend informieren und diskutieren zu können, einer allgemeinen Abstimmung zu unterziehen, die sich nur in Schwarz und Weiss, mit Ja oder Nein entscheiden lässt. Dafür geeignet sind Parlamente. Damien: «Wir leben eine antiautoritäre Tradition, in der sich Freiheit in der Fähigkeit ausdrückt, selbstbestimmt und ohne Verpflichtung gegenüber Dritten entscheiden zu können. Autorität wird jedoch oft auch mit ihrem Missbrauch verwechselt. Dabei hat sie ohne Respekt und Reziprozität keinen Bestand. Unabhängig davon, wie eine Gruppe in Grösse oder Intention geartet sein mag, so müssen doch jene, auf die Autorität ausgeübt wird, in ihrer Bindung zur Autoritätsgruppe das Gefühl haben, erhöht zu werden, zu wachsen [...]. Wie also ist der Werteverlust im Zusammenhang mit einer legitimen Autorität zu sehen?» Auf Dostojewskis Grundsatz- frage «Vor wem sollen wir uns beugen?» antwortet Damien: «Vor einer brüderlichen Mehrheit, die mir erlaubt, mich zu entwickeln, ohne dabei meine Interessen $\mathrm{zu}$ verletzen und die mir dabei immer die Freiheit der Kritik lässt.»

Der Philosoph in der Rolle des Herrscherberaters: «Jeder (auch die Autoritätsperson) ist ein Suchender in der Ungewissheit und muss zu seiner Entwicklung die Meinung Dritter hören. Zur Entwicklung dieser legitimen Autorität braucht es Qualitäten wie gebildete Intelligenz, Urteilsvermögen und konsequente Kontinuität. Diese Qualitäten erwerben sich durch die Begegnung mit anderen Standpunkten.» Letzteres ist unabdingbar.

«Ich spreche hier von einer «Ästhetik/Ethik» der Autorität und meine damit, dass diese Autorität nur existent wird, wenn ihr realer Rahmen durch eine symbolische Macht erhöht wird. Wenn der jeweilige reale Autoritätsrahmen die Überhand über den symbolischen Autoritätswert einer betroffenen Person oder Institution gewinnt, wird Autorität zur Karikatur.»

Hier, so glaube ich (J.M.), müssen die echten kulturpolitischen Unterschiede betont werden: Der obige Diskurs trägt offenkundig den Stempel Frankreichs und seiner Geschichte, die Prägung von Verhaltensmustern, die sich monarchistische Züge bewahrt haben. In unserem Land, in dem ein Bundesrat mit dem Velo zum Büro fährt und Minister auf ihren Reisen kaum Personenschutz in Anspruch nehmen, hat dieser «symbolische Rahmen» sicherlich nicht dasselbe Gewicht. Bislang erkenne ich hier keine eklatant geminderte Nähe zwischen den Staatsbürgern und ihren gewählten Mandatsträgern. Auch keine Minderung des eher familiären Respekts, der diesen entgegengebracht wird (richtig ist jedoch, dass das dem Amt beigemessene Prestige hier im waadtländischen Milieu nicht mehr dasselbe ist wie noch vor fünfzig Jahren) [3]

Im Sinne eines neuen politischen Geistes: «Der Wille zu einem neuen cogito, einem cogito, das in Relation zu gegenseitigen Verpflichtungen und Absprachen steht und letztlich ein neues Ideal des Wir ermöglichen könnte.» Damien: «Ich sehe mich in der Tradition der kompetitiven Kooperation. Weder das Individuum noch das Kapital schaffen Mehrwert, sondern das kollektive Wir der Koordination.» 